\title{
COVID-19 and Brazilian's mental health: Risk factors and related symptoms
}

\author{
Jaqueline P. Giordani' \\ Dttps://orcid.org/0000-0002-2607-7132 \\ Carolina P. Lima' \\ iD https://orcid.org/0000-0001-5103-2203 \\ Michael de Q. Duarte ${ }^{1}$ \\ https://orcid.org/0000-0002-5024-8587 \\ Manuela A. da S. Santo' \\ https://orcid.org/0000-0003-0127-1331 \\ Letícia S. Czepielewski ${ }^{1}$ \\ https://orcid.org/0000-0002-3898-0273 \\ Clarissa Marceli Trentini ${ }^{1}$ \\ https://orcid.org/0000-0002-2607-7132
}

To cite this article: Giordani, J. P., Lima, C. P., Duarte, M. Q., Santo, M. A. S., Czepielewski, L. S., \& Trentini, C. M. (2021). COVID-19 and Brazilian's mental health: Risk factors and related symptoms. Psicologia: Teoria e Prática, 23(1), 1-19. doi:10.5935/1980-6906/ ePTPC1913993

Submission: $31 / 08 / 2020$

Acceptance: $30 / 10 / 2020$

1 Federal University of Rio Grande do Sul (UFRGS), Porto Alegre, RS, Brazil. 


\begin{abstract}
In a pandemic, it is necessary to understand who is at higher risk for psychological difficulties. Thus, we aim to investigate psychological symptoms in a Brazilian sample during the COVID-19 pandemic and their associations with sociodemographic, health, and pandemic-related variables. We included 1358 individuals assessed via an online survey through a questionnaire that included sociodemographic and other questions related to the pandemic and the SRQ-20. The results showed that younger adults and women were at a higher risk for minor mental disorders. An investigation about subgroups revealed three clusters representing symptom's severity. The cluster with most symptoms was younger people, had their income most impacted by the pandemic, and had more frequent diagnoses of mental disorders. The subgroups were discriminated mostly due to cognitive-emotional symptoms. We discussed the determinants that can contribute to mental health vulnerability and highlighted the need for state actions for those more vulnerable.
\end{abstract}

Keywords: COVID-19; mental health; pandemic; risk-factors; psychopathology.

\title{
COVID-19 E SAÚDE MENTAL DE BRASILEIROS: FATORES DE RISCO E SINTOMAS ASSOCIADOS
}

\section{Resumo}

Em uma pandemia, é necessário entender quem possui maior risco de dificuldades psicológicas. O objetivo deste estudo foi investigar os sintomas psicológicos mais prevalentes em uma amostra brasileira, durante a pandemia da COVID-19 e associações com variáveis sociodemográficas, de saúde e pandêmicas. 1.358 indivíduos responderam a um survey online por meio de questionário, que incluiu questões sociodemográficas e relacionadas à pandemia, e o SRQ-20. Os resultados mostraram que mais jovens e mulheres estão em maior risco de transtornos mentais menores (MMD). Uma investigação sobre subgrupos revelou três grupos que representam a gravidade dos sintomas. O cluster com mais sintomas era mais jovem, teve sua renda mais impactada pela pandemia e tinha diagnósticos de transtornos mentais mais frequentemente. Os subgrupos foram discriminados principalmente devido a sintomas cognitivo-emocionais. Discutimos os determinantes que podem contribuir para a vulnerabilidade em saúde mental e destacamos a necessidade de ações estatais para os mais vulneráveis.

Palavras-chave: COVID-19; saúde mental; pandemia; fatores de risco; psicopatologia. 


\title{
COVID-19 Y SALUD MENTAL DE BRASILEÑOS: FACTORES DE RIESGO Y SÍNTOMAS ASOCIADOS
}

\begin{abstract}
Resumen
En una pandemia, es necesario comprender quién está en mayor riesgo de tener dificultades psicológicas. El objetivo fue investigar los síntomas psicológicos más prevalentes en una muestra brasileña, durante la pandemia de COVID-19, y las asociaciones con variables sociodemográficas, de salud y pandémicas. 1358 personas que fueron evaluadas a través de un cuestionario que incluía aspectos sociodemográficos y relacionados con la pandemia y el SRQ-20. Los resultados mostraron que más jóvenes y mujeres tienen un mayor riesgo de trastornos mentales menores. Una investigación en subgrupos reveló tres grupos que representan la gravedad de los síntomas. El grupo con más síntomas era más joven, sus ingresos se vieron más afectados por la pandemia y tenían más diagnósticos de trastornos mentales. Los subgrupos fueron discriminados principalmente por síntomas cognitivo-emocionales. Discutimos los determinantes que pueden contribuir a la vulnerabilidad en salud mental y resaltamos la necesidad de acciones estatales para los más vulnerables.

Palabras clave: COVID-19; salud mental; pandemia; factores de riesgo; psicopatología.
\end{abstract}

\section{Introduction}

Epidemics do not affect populations in the same way. Inequalities can worsen the spread of infections (Yao, Chen, \& Xu, 2020), so it is essential to understand health risk factors, including psychological ones. A global pandemic may cause a parallel epidemic of fear, anxiety, and depression, especially for people who are more influenced by the emotional responses brought on by it (Yao, Chen, $\& \mathrm{Xu}, 2020)$. This unprecedented situation has raised questions regarding the nature and the determinants of mental health promotion and care.

In December 2019, a novel coronavirus was identified, originating in Wuhan, China. The outbreak of acute infectious pneumonia caused by it widely and rapidly spread in China and several other countries. The World Health Organization (WHO) declared, in January 2020, that this outbreak of the disease caused by the novel coronavirus (COVID-19) constituted a Public Health Emergency of International Importance - the Organization's highest level of alert (OPAS, 2020; WHO, 2020). On February 26, 2020, Brazil confirmed the first case of COVID-19. On March 11, 2020, COVID-19 was classified by the WHO as a pandemic (OPAS, 2020), which is 
mainly characterized by the spread of a disease in a geographically extended area, affecting a relatively large number of people (Morens, Folkers, \& Fauci, 2009).

Studies have indicated that, in countries greatly affected by COVID-19, the pandemic brought the risk of infection and death and high psychological pressure on people (Cao et al., 2020; Xiao, 2020). Strict isolation measures (Cao et al., 2020), delay in starting school and university classes (Cao et al., 2020), lack of interpersonal communication (Xiao, 2020), and the need to manage the pandemic health risks could be some of the reasons of psychological distress in the pandemic context. Social distancing and quarantine may also reduce the availability of timely psychological interventions (Xiao, 2020). The impact on mental health seems substantial and long-lasting, influencing a broad range of daily activities (Cao et al., 2020).

Therefore, the objective of this study was to investigate the most prevalent psychopathological symptoms in a Brazilian sample during the COVID-19 pandemic and their associations with sociodemographic, health, and pandemic-related variables. Specifically, we aimed to investigate data-driven subgroups of symptoms, symptoms that might contribute most to clusters of severity, latent dimensions in SRQ-20, and also to make subgroup comparisons.

\section{Methods}

\subsection{Procedures and ethical considerations}

The project was approved by the National Research Ethics Commission (CONEP), $n^{\circ}$ 3.959.863, and CAAE 30114520.1.0000.5334. The research and the requirements for participation were presented in participant recruitment invitations sent via social networks. Participants answered the questionnaire through an online survey and agreed with an informed consent form. Once completed, participants were granted access to illustrated cards with tips on mental health prevention and promotion that followed information recommended by the WHO and the Brazilian Ministry of Health.

Data were collected between April 18 and May 12, 2020. On May 13, 2020, Brazil registered 188,974 confirmed cases and 13,149 deaths due to the coronavirus (Ministério da Saúde, 2020b). There were differences between the country's States and regions in terms of occupation of intensive care unit (ICU) beds, the rate of 
contamination, and deaths. Nevertheless, several mayors and governors across the country had stipulated decrees of social distance and suspension of non-essential activities. One thousand three hundred fifty-eight individuals from Brazil took part in the survey, located in the regions: $1.55 \%$ north, $8.85 \%$ north-east, $2.73 \%$ centerwest, $16.15 \%$ south-east, and $70.72 \%$ south.

\subsection{Instruments}

Participants answered a questionnaire with 18 self-reported items that included sociodemographic questions and other questions regarding social isolation/social distancing, access to information about the pandemic, and whether the participant is in the high-risk group for developing severe COVID-19 (e.g., people aged 60 and over, people with cardiovascular disease, diabetes or chronic lung disease, according to OPAS (2020)). Additionally, they completed the Self Reporting Questionnaire (SRQ-20), validated in Brazil by Santos, Araújo, Pinho, and Silva (2011), designed to screen for psychiatric disturbances, especially in primary health care settings in developing countries. SRQ-2O is an objective and straightforward scale covering many important psychopathology areas related to "neurotic" symptoms. It was designed as a self-administered scale. Items are scores 0 or 1 , the latter indicating that the symptom was present during the past month (WHO, 1994 - A User's Guide to the Self Reporting Questionnaire - SRQ). We considered the SRQ-20 total score and individual item responses to investigate psychological symptoms and risk for minor mental disorders.

\subsection{Participants}

There were 1358 participants from all regions of the country. The inclusion criteria were: to be Brazilian, over 18 years old, and living in Brazil during the outbreak of the COVID-19 pandemic in 2020. No exclusion criteria were foreseen.

Participants reported being located in the regions: $1.55 \%$ north, $8.85 \%$ north-east, $2.73 \%$ center-west, $16.15 \%$ south-east, and $70.72 \%$ south. They were $36.37( \pm 12.40)$ years old on average, and $82.03 \%$ were women. $24.15 \%$ reported being at a high risk of severe COVID-19, and $44.18 \%$ were currently living with someone at a high risk. $7.73 \%$ were living alone. Some form of social isolation was being followed by $91.02 \%$ of the participants, and the duration of social isolation was $28.20( \pm 9.21)$ days. $44.80 \%$ of the participants had their income recently 
reduced because of the pandemic. SRQ-20 mean total score was $7.06( \pm 4.82)$, and $50.15 \%$ of the participants scored seven or more. $36.18 \%$ of the participants reported having a previous or current psychiatric disorder diagnosis, and 66.57\% had some type of mental health support.

\subsection{Data Analysis}

We performed analyses in $\mathrm{R}$ (version 4.0.0) and RStudio (version 1.3.959). Statistical significance was $p<0.05$ (two-tailed) for all tests. Descriptive data were expressed as mean and standard deviation. We performed hypothesis testing in four steps. We first described our sample and tested the relationships between SRQ-20 and other variables using Pearson's correlation and linear regression models with interaction terms. Second, we performed a hierarchical cluster analysis (HCA) using Ward's method considering the 20 items of the SRQ-20 to investigate subgroups of mental health difficulties. Then, we compared these data-driven subgroups regarding sociodemographic and other variables. Third, to explore the symptoms that might contribute more to the data-driven clusters, we conducted a discriminant analysis with the 20 items of the SRQ-20 discriminating the datadriven clusters. We then analyzed the discriminant loadings, e.g., the correlations between each discriminating variable and the standardized canonical discriminant functions. Variables with $r>30$ were considered relevant. Fourth, to further understand the symptoms presented by our sample, we tested for latent dimensions for SRQ-20 through principal components analysis (PCA) with orthogonal rotation (varimax) considering the 20 items of the SRQ-20.

\section{Results}

\subsection{Investigating the relationship between mental health and other variables}

SRQ-20 total score was negatively related to age $(r=-.37, p<.001)$ and income $(r=-.25, p<.001)$, and women had increased scores $(t(1356)=-4.392, p$ $<.001$, Cohen's $d=.31$ ). Interestingly, SRQ -20 total score was slightly associated to how much information were being accessed related to number of infected people or deaths $(r=.10, p=.0002)$, but it was not linked to accessing information related to the prevention of the novel coronavirus and self-care $(r=.05, p=.064)$. For the 
people in social isolation, the duration of isolation was not related to SRQ-20 total score $(r=.04, p=.188)$. People who had current or prior self-referred diagnosis of psychiatric disorder had increased SRQ-20 scores $(t(902)=-9.321, p<.001$, Cohen's $d=.65)$, as did the participants under some type of mental health support at any time of their lives $(t(1356)=-4.02, p<.001$, Cohen's $d=.23$ ).

Linear regression models were performed to investigate possible interactions between variables. The model that predicted SRQ-20 total score including age, gender, income, previous or current psychiatric diagnosis, and how much information was being accessed on the number of infected and deaths $(F(5,891)=$ 52.85, $\mathrm{p}<.001$, Adj. $\left.\mathrm{R}^{2}=.22\right)$ showed independent main effects for variables $(\mathrm{p}<$ .001) and an additional interaction between gender and accessing information ( $\mathrm{t}=$ 2.074, $p=.038$ ). This suggests that, for women, accessing information related to the number of infections and deaths due to COVID-19 was more related to mental health symptoms than for men.

\subsection{Investigating subgroups of symptoms report}

To investigate the presence of subgroups of mental health symptoms, a hierarchical cluster analysis (HCA) using Ward's method was performed considering the 20 items of SRQ-20. A three-solution was found through a dendrogram inspection, comprising $44.62 \%$ of participants on cluster $1(n=606), 39.62 \%$ on cluster $2(n=538)$ and $15.75 \%$ on cluster $3(n=214)$.

2.2 Subgroups comparisons

The three subgroups showed differences in SRQ-20 total score [cluster1: $2.85( \pm 2.15)$, cluster2: $9.09( \pm 2.82)$, cluster3: $13.90( \pm 2.66) ; F(2,1355)=1815.0, p$ $<.001)$ ], suggesting that they represented levels of the severity of the participants' symptoms (Figure 3.2.1). These subgroups differed in positive screening for mental disturbances $\left(\chi^{2}(2)=897.6, p<.001\right)$, age $(F(2,1355)=82.37, p<.001)$, gender $\left(\chi^{2}(2)=27.33, p<.001\right)$, income recently reduced because of the pandemic $\left(\chi^{2}(2)\right.$ $=10.603, p=.005)$, following some type of social isolation $\left(\chi^{2}(2)=7.149 p=.03\right)$, under mental health support at any time $\left(\chi^{2}(2)=16.072, p<.001\right)$, and current or previous psychiatric diagnosis $\left(\chi^{2}(2)=56.823, \mathrm{p}<.001\right)$. Nonetheless, they didn't show differences regarding being at a high risk of severe COVID-19 $\left(\chi^{2}(2)=3.121\right.$, $p=.209)$ or living with someone at a high risk $\left(\chi^{2}(2)=4.518, p=.10\right)$. Groups means and SDs are described in Figure 3.2.2. 


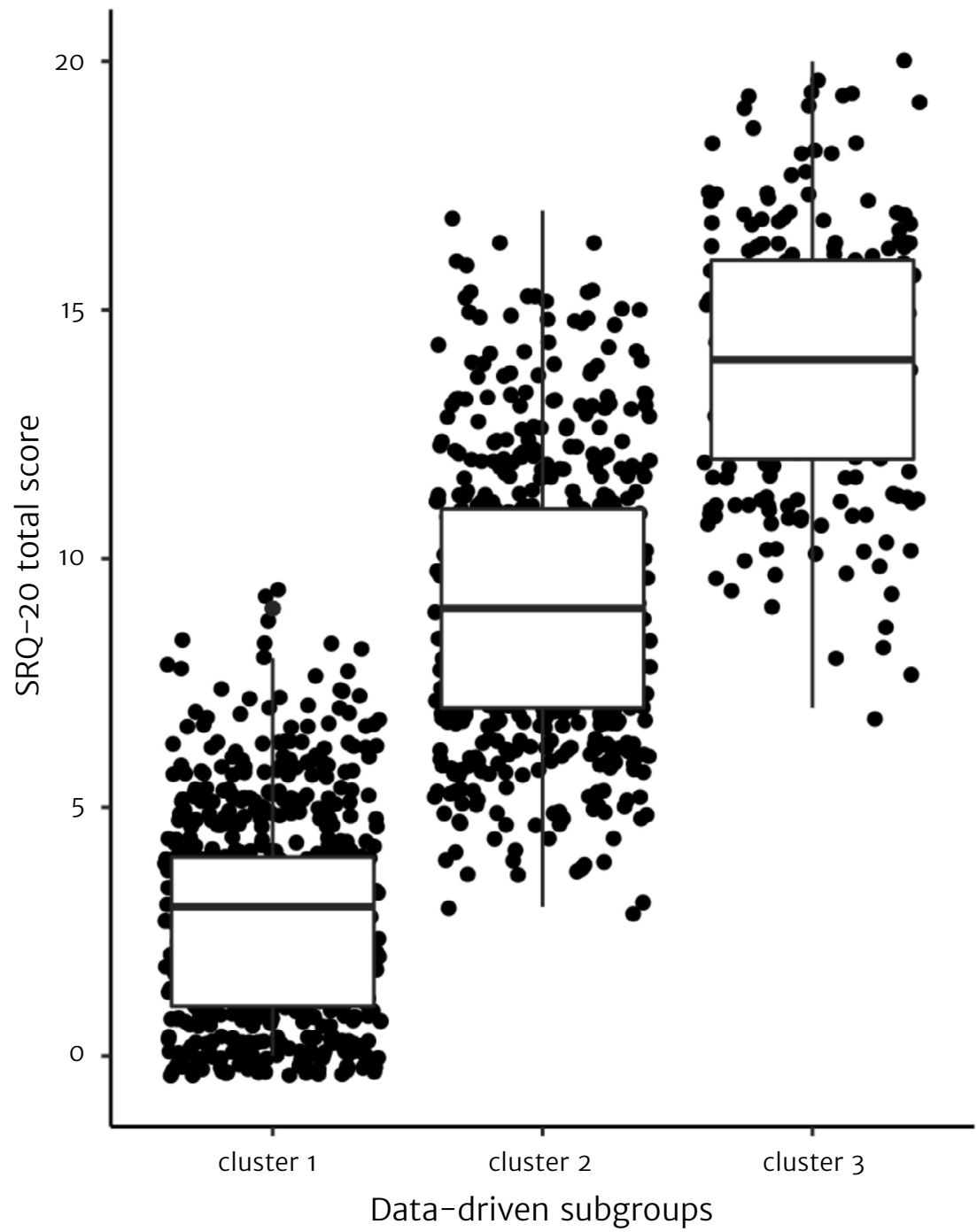

Figure 3.2.1. Differences in SRQ-20 total score of the three subgroups of participants. 
Figure 3.2.2. Groups' means and SDs.

\begin{tabular}{|c|c|c|c|c|}
\hline & $\begin{array}{c}\text { TOTAL } \\
(n=1358)\end{array}$ & $\begin{array}{l}\text { cluster1 } \\
(n=606)\end{array}$ & $\begin{array}{l}\text { cluster } 2 \\
(\mathrm{n}=538)\end{array}$ & $\begin{array}{l}\text { cluster3 } \\
(n=214)\end{array}$ \\
\hline Age [Mean (SD)] & $36.37(12.40)$ & $40.34(13.03)$ & $34.84(10.98)$ & $28.95(9.31)$ \\
\hline Gender [\% Women] & $82 \%$ & $76 \%$ & $88 \%$ & $82 \%$ \\
\hline Following social isolation [\%] & $91 \%$ & $90 \%$ & $90 \%$ & $96 \%$ \\
\hline $\begin{array}{l}\text { Duration of isolation [Mean } \\
\text { (SD)] }\end{array}$ & $28.20(9.21)$ & $28.14(8.93)$ & $28.06(9.44)$ & $28.74(9.37)$ \\
\hline $\begin{array}{l}\text { SRQ-20 Total Score [Mean } \\
\text { (SD)] }\end{array}$ & $7.06(4.82)$ & $2.85(2.15)$ & $9.09(2.82)$ & $13.90(2.66)$ \\
\hline $\begin{array}{l}\text { SRQ-20 positive screening for } \\
\text { mental disturbances }(\geq 7)[\%]\end{array}$ & $50 \%$ & $5 \%$ & $81 \%$ & $100 \%$ \\
\hline $\begin{array}{l}\text { Income recently reduced } \\
\text { because of the pandemic [\%] }\end{array}$ & $45 \%$ & $42 \%$ & $44 \%$ & $55 \%$ \\
\hline $\begin{array}{l}\text { Under any type of mental } \\
\text { health support [\%] }\end{array}$ & $67 \%$ & $61 \%$ & $71 \%$ & $72 \%$ \\
\hline $\begin{array}{l}\text { Current or previous diagnosis } \\
\text { of mental disorder [\%] }\end{array}$ & $35 \%$ & $23 \%$ & $39 \%$ & $56 \%$ \\
\hline $\begin{array}{l}\text { Being at a high risk of severe } \\
\text { COVID-19 [\%] }\end{array}$ & $24 \%$ & $22 \%$ & $25 \%$ & $27 \%$ \\
\hline $\begin{array}{l}\text { Living with someone at a high } \\
\text { risk of severe COVID-19 [\%] }\end{array}$ & $44 \%$ & $42 \%$ & $44 \%$ & $50 \%$ \\
\hline $\begin{array}{l}\text { How much information was } \\
\text { being accessed on the number } \\
\text { of infected and deaths due to } \\
\text { COVID-19 [Mean (SD)] }\end{array}$ & $6.30(2.70)$ & $6.06(2.81)$ & $6.43(2.59)$ & $6.62(2.63)$ \\
\hline $\begin{array}{l}\text { How much information } \\
\text { was being accessed on the } \\
\text { prevention of COVID-19 and } \\
\text { self-care [Mean (SD)] }\end{array}$ & $7.17(2.53)$ & $7.06(2.55)$ & $7.21(2.51)$ & $7.41(2.50)$ \\
\hline
\end{tabular}

\subsection{Investigating the symptoms that might contribute most to clusters of severity}

The discriminant analysis including all items of the SRQ-20 revealed two discriminant functions for the clusters. The first explained $80 \%$ of the variance and the second $20 \%$ (Wilks' $\lambda=.126, \chi^{2}=2788.159, p<.001$; Wilks' $\lambda=.545, \chi^{2}=$ $816.422, p<0.001$, respectively). The model correctly classified $89.7 \%$ of the cases, evidencing the validity of the three clusters. The first function better explained the variance and better discriminated between clusters 1 and 3 . When we considered this function, the items that were more important to classify into clusters through 
correlations between discriminating variables and discriminant functions were (in order of importance): lost interest in things $(r=.401)$, feel tired all the time $(r=$ $.388)$, easily tired $(r=.384)$, trouble thinking clearly $(r=.380)$, find it difficult to make decisions $(r=.327)$, find it difficult to enjoy your daily activities $(r=.314)$, and feel unhappy $(r=306)$.

\subsection{Investigating latent dimensions in SRQ-20}

A principal components analysis (PCA) was conducted on the 20 items of the SRQ-20 with orthogonal rotation (varimax). The Kaiser-Meyer-Olkin measure verified the sampling adequacy for the analysis $\mathrm{KMO}=.91$, and all $\mathrm{KMO}$ values for individual items were $>.80$, which is well above the acceptable limit of .5. Bartlett's test of sphericity, $\chi^{2}(190)=7174.371, p<.001$, indicated that correlations between items were sufficiently large for PCA. An initial analysis was run to obtain eigenvalues for each component in the data. Three components had eigenvalues over Kaiser's criterion of 1 and, in combination, they explained $43.23 \%$ of the variance. The scree plot showed inflections that would justify retaining three components. Given the large sample size and the convergence of the scree plot and Kaiser's criterion on the three components, three components were retained in the final analysis. Figure 3.4.1 shows the factor loadings after rotation. The items that cluster on the same components suggest that component 1 represents Cognitiveemotional symptoms, component 2 Psychosomatic symptoms, and component 3 Life purpose related symptoms. 
Figure 3.4.1. Factor loads in clusters after rotation.

\begin{tabular}{|c|c|c|c|}
\hline \multirow[b]{2}{*}{ SRQ-20 Item } & \multicolumn{3}{|c|}{$\begin{array}{l}\text { Varimax rotated } \\
\text { factor loadings }\end{array}$} \\
\hline & PC1 & PC2 & $\mathrm{PC}_{3}$ \\
\hline Do you find it difficult to enjoy your daily activities? & .73 & & \\
\hline Do you feel unhappy? & .71 & & \\
\hline Do you feel nervous, tense, or worried? & .65 & & \\
\hline Have you lost interest in things? & .59 & & \\
\hline Do you find it difficult to make decisions? & .55 & & \\
\hline Are you easily tired? & .53 & & \\
\hline Do you have trouble thinking clearly? & .53 & & \\
\hline Do you feel tired all the time? & .51 & & \\
\hline Is your daily work suffering? & .48 & & \\
\hline Do you cry more than usual? & .48 & & \\
\hline Are you easily frightened? & .35 & & \\
\hline Do you have uncomfortable feelings in your stomach? & & .81 & \\
\hline Is your digestion poor? & & .79 & \\
\hline Do you often have headaches? & & .49 & \\
\hline Do you sleep badly? & & .47 & \\
\hline Is your appetite poor? & & .40 & \\
\hline Do your hands shake? & & .38 & \\
\hline Are you unable to play a useful part in life? & & & .74 \\
\hline Do you feel that you are a worthless person? & & & .70 \\
\hline Has the thought of ending your life been on your mind? & & & .57 \\
\hline
\end{tabular}

\section{Discussion}

The results demonstrate that people are suffering during this period due to the COVID-19 pandemic, with more than half of the participants presenting risk symptoms for minor mental disorders. The results that will be discussed are: 1) younger adults presented more risk for minor mental disorders; 2) being a woman posed more risk for experiencing mental health symptoms; 3 ) women's access to information on the number of infections and deaths due to COVID-19 was more related to symptoms than men's access; 4) individuals who were in cluster 1 
presented many protective factors for developing minor mental disorders, such as maintenance of income, less frequency of mental disorders diagnosis, and being older, in comparison with cluster 3; 5) isolation was a significant risk factor for mental illness specifically for cluster $3 ; 6$ ) the variables that best discriminated between groups were cognitive-emotional symptoms that were mostly related to symptoms of anhedonia in addition to depressive symptomatology.

\subsection{Relationship between mental health and other variables}

First, age was a relevant factor in the identification of psychopathological symptoms. Younger adults were at an increased risk for minor mental disorders. A previous study has shown that being older is negatively associated with mental disorders during the pandemic, such as depression, anxiety, and post-traumatic stress disorder (PTSD) (González-Sanguino et al., 2020). These findings point to a trend described in the literature that older adults experience adverse events as less unpleasant than younger adults, have more variability in coping strategies, and that the life experience could provide a better capacity for affect regulation (Neubauer, Smyth, \& Sliwinski, 2019). Also, younger adults could experience anxiety symptoms with higher intensity and a general worsening of their mental health in the pandemic, as they are more susceptible to economic impacts and might have difficulties in achieving expected academic levels and entering the job market (Cao et al., 2020; González-Sanguino et al., 2020).

Likewise, being a woman was a risk factor for increased mental suffering in the current context. Research on the mental health of populations experiencing this pandemic has found similar results (Chang, Yuan, \& Wang, 2020; GonzálezSanguino et al., 2020), indicating that women should be a priority for mental health interventions in the context of COVID-19. Furthermore, it is essential to pay attention to the challenges of gender inequality experienced by women, which became aggravated during the pandemic. Situations, such as domestic violence, primary care of children, and overload of domestic tasks consistently affect women's physical and mental health. At the same time, there might be, at that moment, mitigation of their support network with no effective alternatives being offered (Gausman \& Langer, 2020).

Moreover, women's access to information on the number of infections and deaths due to COVID-19 was more related to mental health symptoms than men's 
access to this information. That can be explained, in part, by the fact that women represent the majority of the workforce of health professionals who are working during the pandemic (Gausman \& Langer, 2020), in addition to having higher rates of empathy (Nascimento et al., 2018). Further reports highlight this relationship in the pandemic context. A study by Lima et al. (2020), carried out in Brazil, showed that women perceive themselves as more prone to the risk of contamination by COVID-19 than men, revealing their greater sense of self-care and concern with their health. A study in Spain showed that being a woman and being exposed to more information are predictors of psychological problems, though they did not discriminate which type of information (González-Sanguino et al., 2020). Another study in China found that excessive negative information related to the pandemic was associated with an increased likelihood of depression (Chang, Yuan, \& Wang, 2020). Thus, our results are supported by the literature and add relevant information for Brazil that could help develop health communication and prevention guidelines.

\subsection{Subgroups of symptoms report}

The investigation about the presence of subgroups of mental health symptoms revealed three clusters. People in cluster 1 presented all the protective factors found in the analyses to decrease the risk for minor mental disorders, which was already indicated by the mean of these participants in SRQ-20. In this cluster, the mean age was higher than in the other clusters, which was demonstrated in previous analyses as a protective factor. This cluster was also the one that, compared to the others, comprised fewer people that had their income reduced due to the pandemic (42\%). Having financial resources at times of economic instability is an important protective factor because it reduces the risk of financial stress, being one less source of concern for subsistence maintenance, thus, contributing to better mental health indexes (González-Sanguino et al., 2020).

The participants of cluster 1 presented the lowest percentage of previous self-referred diagnoses of mental disorders, especially in comparison with cluster 3. This data corroborates what is presented in the scientific literature, which shows that people with a previous mental disorder diagnosis have an increased risk of developing new mental illness episodes or suffering during the pandemic (Yao, Chen, \& Xu, 2020). Furthermore, most people with psychiatric disorders attend regular outpatient visits for evaluations and prescriptions. Regulations on travel 
and social isolation worldwide have resulted in these regular visits becoming more difficult or even impractical. Another result showed that cluster 1 included fewer individuals who reported ever being under some form of mental health support. This finding possibly indicates individuals who have fewer mental health needs through life, and not that being in mental health support is, in some way, harmful.

The analyses performed showed that isolation is a significant risk factor for mental illness, specifically for cluster 3 . The duration of isolation was not significant for any of the 3 clusters. These data are relevant because they reinforce the idea that one of the only effective measures to combat the pandemic at the moment, which is social isolation/social distancing, possibly does not pose a risk to most of the population's mental health. Conversely, the feeling of loneliness associated and aggravated by the pandemic might represent a risk factor for mental health problems. People at a higher risk of mental disorders may also be more vulnerable to social change due to a pandemic, as they tend to be previously more socially isolated and have smaller and worse quality support networks (Beller, \& Wagner, 2018).

\subsection{Symptoms that might contribute most to clusters of severity}

In this sample, the discriminant analysis showed two discriminant functions for the clusters. The first function better explained the data, especially between cluster 1 (comprising individuals with minimal symptomatology or minimal risk for mental disorders) and cluster 3 (composed of individuals with higher severity of symptoms, measured by SRQ-2O score). All variables that best discriminated between groups were in component 1 (named cognitive-emotional symptoms). The discriminant variables indicate depressive symptoms: loss of interest, fatigue, cognitive difficulties, loss of pleasure, and negative affect (APA, 2014). Recently studies during the COVID-19 pandemic have demonstrated an elevated prevalence of depressive symptoms, along with other clinical manifestations (GonzálezSanguino et al., 2020). When looking at the specific symptoms, it is possible to observe that "feeling unhappy," "trouble thinking clearly," and "find it difficult to make decisions" could be related in this sample to worsening mental health, thus, it should be a target in clinical health interviews or interventions.

Other items referred to as discriminants could be relevant to map individuals at increased risk for mental disorders. For example, the variable that best 
discriminated between clusters was "loss of interest in things." Usually, the loss of interest is an indicator of anhedonia, characterized by a lowered capacity to experience pleasure and decreased motivation for this objective (Ho \& Sommers, 2013). This capacity to feel pleasure varies because of the subjective character of the problem and is especially present when the individual previously perceived experiences as pleasurable (Ho \& Sommers, 2013). Since another discriminant variable for this sample was "find it difficult to enjoy daily activities," it seems that cluster 3 exhibits more intense states of anhedonia than cluster 1.

Moreover, although not exclusive, it can be inferred that symptoms of tiredness (second and third most important discriminants in this sample) may be related to loss of energy or motivation, cited as symptoms of anhedonia. A study with young people referred that effort and motivation difficulties could be related to low energy and fatigue (Watson, Harvey, McCabe, \& Reynolds, 2019). The pandemic could also be increasing the burden on a person's responsibilities, affecting routine and sleep, possibly leading to physical exhaustion.

Also, it is crucial to address the role of anhedonia in psychosocial functioning. The pandemic potentially burdens the social support network and the maintenance of relationships and could contribute to isolation and a sense of loneliness. These concurrent experiences (pandemic characteristics and anhedonia symptoms) may be especially harmful to functioning and mental health. Hagerty and Williams (2020) argue that decreasing opportunities of social connections during the pandemic could further limit the brain's reward circuit's activation, thereby exacerbating symptoms related to anhedonia. Therefore, the results could indicate that people in cluster 3 may be at a higher risk of aggravated psychosocial problems during the COVID-19 pandemic and that these relationships can become a harmful cycle because of the social particularities of the pandemic. However, other variables, like socioeconomic issues, could be further contributing to this probable interaction.

As cluster 3 had more mental health difficulties and a higher prevalence of individuals with a previous diagnosis of mental disorder (56\%), the described discriminant symptoms could serve as red flags for the risk of recurrence of psychopathologies. Previous studies showed that people diagnosed with mental disorders could suffer more intensively with mental health problems during the pandemic, because of the possible higher susceptibility to stress, than the general 
population (Yao, Chen, \& Xu, 2020). However, it is worth mentioning that we do not know which mental disorders were previously identified in the sample participants, so the results should be interpreted with caution.

In conclusion, the COVID-19 pandemic appears to cause physical illness and impacts on the mental health of populations due to the policies of social isolation adopted worldwide, the recurrent news of deaths and contamination, financial insecurity, and relational challenges imposed by this new reality. Our study sought to investigate how the novel coronavirus pandemic could be associated with a burden to Brazilians' mental health in 2020. The results showed that most people had reported symptoms that indicate a risk for minor mental disorders but that both the typology and the intensity of these symptoms were different across the sample.

There are some limitations of the study concerning the sample's representativeness. There was a gap between the region where the participants lived (most were from southern Brazil) and their gender (82.03\% were women). Further, it was a non-probabilistic convenience sample. These results limit the data's generalization to other contexts or populations with different characteristics. Moreover, although SRQ-20 indicates the presence of psychological symptoms in a population, it cannot alone determine psychopathology. We emphasize that, as we have no results from before the pandemic, the results found are not necessarily specific to this moment. Complementary instruments would be needed to assess the mental health and possible psychopathologies present in the population during the pandemic in a more profound way.

The risk factors pointed out in this study can help develop public policies aimed explicitly at those who are more vulnerable to mental illness. After a crisis and a global recession, a physically and mentally healthy population is fundamental for recovering the economy. Thus, it seems imperative for health professionals to ask about cognitive-emotional symptoms, which may be associated with an increased risk of psychological distress. Also, programs to promote positive experiences and online interactions might increase people's motivation and social repertoire to undergo more positive effects in their daily lives, contributing to maintaining psychological health in this context. 


\section{References}

American Psychiatric Association (2014). DSM-5: Manual diagnóstico e estatístico de transtornos mentais. Porto Alegre: Artmed Editora.

Banerjee, D. (2020). The COVID-19 outbreak: Crucial role the psychiatrists can play. Asian Journal of Psychiatry, 50. doi:10.1016/j.ajp.2020.102014

Beller, J., \& Wagner, A. (2018). Desemaranhamento da solidão: Efeitos diferenciais da solidão subjetiva, qualidade da rede, tamanho da rede e viver sozinho na saúde física, mental e cognitiva. Jornal do Envelhecimento e Saúde, 30(4), 521-539. doi: $10.1177 / 0898264316685843$

Cao, W., Fang, Z., Hou, G., Han, M., Xu, X., Dong, J., \& Zheng, J. (2020). The psychological impact of the COVID-19 epidemic on college students in China. Psychiatry Research, 287. doi:10.1016/j.psychres.2020.112934

Chang, J., Yuan, Y., \& Wang, D. (2020). Mental health status and its influencing factors among college students during the epidemic of COVID-19. Journal of Southern Medical University, 4O(2), 171. doi:10.12122/j.issn.1673-4254.2020.02.06

Gausman, J., \& Langer, A. (2020). Sex and gender disparities in the COVID-19 pandemic. Journal of Women's Health, 29(4), 465-466. doi:10.1089/jwh.2020.8472

González-Sanguino, C., Ausín, B., ÁngelCastellanos, M., Saiz, J., López-Gómez, A., Ugidos, C., \& Muñoz, M. (2020). Mental health consequences during the initial stage of the 2020 Coronavirus pandemic (COVID-19) in Spain. Brain, Behavior, and Immunity, 87, 172-176. doi:10.1016/j.bbi.2020.05.040

Hagerty, S. L., \& Williams, L. M. (2020). The impact of COVID-19 on mental health: The interactive roles of brain biotypes and human connection. Brain, Behavior, \& Immunity-Health, 100078. doi:10.1016/j.bbih.2020.100078

Ho, N., \& Sommers, M. (2013). Anhedonia: A concept analysis. Archives of psychiatric nursing, 27(3), 121-129. doi:10.1016/j.apnu.2013.02.001

Lima, D. L. F., Dias, A. A., Rabelo, R. S., Cruz, I. D. D., Costa, S. C., Nigri, F. M. N., \& Neri, J. R. (2020). COVID-19 no estado do Ceará, Brasil: Comportamentos e crenças na chegada da pandemia. Ciência \& Saúde Coletiva, 25, 1575-1586. doi:10.1590/ $1413-81232020255.07192020$

Ministério da Saúde (2020b).Coronavírus: 188.974 casos confirmados e 78.424 recuperados. Brasil: Agência da Saúde. Retrieved from https://www.saude.gov.br/noticias/agenciasaude/46882-coronavirus-188-974-casos-confirmados-e-78-424-recuperados 
Morens, D. M., Folkers, G. K., \& Fauci, A. S. (2009). What Is a Pandemic? The Journal of Infectious Diseases, 200(7). doi:10.1086/644537

Nascimento, H. C. F., Ferreira Júnior, W. A., Silva, A. M. T. C., Carvalho, I. G. M. D., Bastos, G. C. F. C., \& Almeida, R. J. D. (2018). Análise dos níveis de empatia de estudantes de medicina. Revista Brasileira de Educação Médica, 42(1), 152-160. doi:10.1590/1981-52712018v42n1rb20170057

Neubauer, A. B., Smyth, J. M., \& Sliwinski, M. J. (2019). Age differences in proactive coping with minor hassles in daily life. The Journals of Gerontology, Series B: Psychological Sciences and Social Sciences, 74(1), 7-16. doi:10.1093/geronb/gbyo61

Organização Pan-Americana de Saúde / Organização Mundial da Saúde (OPAS). (2020). Folha informativa - COVID-19 (doença causada pelo novo coronavírus) updated on Jun 9, 2020. Retrieved from https://www.paho.org/bra/index.php?option=com_ content $\&$ view $=$ article $\&$ id $=6101$ : covid19 \& $\mid$ temid $=875$

Santos, K. O., Araújo, T. M., Pinho, P. D. S., Silva, A. C. C. (2011). Avaliação de um instrumento de mensuração de morbidade psíquica: Estudo de validação do Self-Reporting Questionnaire (SRQ-20). Revista Baiana de Saúde Pública, 34(3), 544-560.

Watson, R., Harvey, K., McCabe, C., \& Reynolds, S. (2020). Understanding anhedonia: A qualitative study exploring loss of interest and pleasure in adolescent depression. European Child \& Adolescent Psychiatry, 29(4), 489-499. doi:10.1007/ s00787-019-01364-y

World Health Organization (WHO). (2020). Coronavirus disease 2019 (COVID-19): situation report, 1. Retrieved from https://www.who.int/docs/default-source/coronaviruse/ situation-reports/20200121-sitrep-1-2019-ncov.pdf?sfvrsn=20a99c10_4

World Health Organization (WHO). (1994). A user's guide to the self-reporting questionnaire (SRQ) (No. WHO/MNH/PSF/94.8. Unpublished). World Health Organization. Retrieved from https://apps.who.int/iris/bitstream/handle/10665/61113/WHO_ MNH_PSF_94.8.pdf

Xiao, C. (2020). A novel approach of consultation on 2019 novel coronavirus (COVID-19)-related psychological and mental problems: Structured letter therapy. Psychiatry investigation, 17(2), 175. doi:10.30773/pi.2020.0047

Yao, H., Chen, J. H., \& Xu, Y. F. (2020). Patients with mental health disorders in the COVID-19 epidemic. The Lancet Psychiatry, 7(4), e21. doi:10.1016/S22150366(20)30090-0 


\section{Authors' notes}

Jaqueline P. Giordani, Graduate Program in Psychology (PPGPSICO), Federal University of Rio Grande do Sul (UFRGS); Carolina P. Lima, Graduate Program in Psychology (PPGPSICO), Federal University of Rio Grande do Sul (UFRGS); Michael de Q. Duarte, Graduate Program in Psychology (PPGPSICO), Federal University of Rio Grande do Sul (UFRGS); Manuela A. da S. Santo, Graduate Program in Psychology (PPGPSICO), Federal University of Rio Grande do Sul (UFRGS); Letícia S. Czepielewski, Graduate Program in Psychology (PPGPSICO), Federal University of Rio Grande do Sul (UFRGS); Clarissa Marceli Trentini, Graduate Program in Psychology (PPGPSICO), Federal University of Rio Grande do Sul (UFRGS).

Correspondence concerning this article should be addressed to Jaqueline Portella Giordani at Ramiro Barcelos, 2600, Sala 225, Porto Alegre, RS, Brazil. CEP 90035-003.

E-mail: jaquelinegiordani@gmail.com

EDITORIAL BOARD

Editor-in-chief

Ana Alexandra Caldas Osório

Section editors

Psychological Evaluation

Alexandre Serpa

Luiz Renato Rodrigues Carreiro

Vera Lúcia Esteves Mateus

\section{Psychology and Education}

Cristiane Silvestre de Paula

Carlo Schmidt

\section{Social Psychology}

Bruna Suguagy do Amaral Dantas

Enzo Banti Bissoli

\section{Clinical Psychology}

Eduardo Fraga Almeida Prado

Marina Monzani da Rocha

Carolina Andrea Ziebold Jorquera

\section{Human Development}

Maria Cristina Triguero Veloz Teixeira

Rosane Lowenthal

\section{Technical support}

Letícia Martinez

Camila Fragoso Ribeiro

\section{EDITORIAL PRODUCTION}

Editorial coordination

Ana Claudia de Mauro

Editorial intern

Júlia Lins Reis

\section{Language editor}

Daniel Leão

Layout

Acqua Estúdio Gráfico 